\title{
Organic acid effect on arsenate bioaccessibility in gastric and alveolar simulated biofluid systems
}

\author{
S.Q. Kong ${ }^{1,2}$, R.A. Root $^{3} \&$ J. Chorover ${ }^{3}$ \\ ${ }^{1}$ School of Environmental Studies and State Key Laboratory of Biogeology and Environmental Geology, \\ China University of Geosciences, Wuhan, P.R. China \\ ${ }^{2}$ Laboratory of Basin Hydrology and Wetland Eco-restoration, School of Environmental Studies, China University of \\ Geosciences, Wuhan, P.R. China \\ ${ }^{3}$ Department of Soil, Water and Environmental Science, University of Arizona, Tucson, AZ, USA
}

\begin{abstract}
The risk posed from incidental ingestion of arsenate-contaminated tailings may depend on sorption of arsenate to oxide surfaces in minerals. Popularly organic matter existing in tailings influenced bioaccessibility of arsenate. Arsenate adsorbed minerals were placed in simulated gastric and alveolar (in vitro) to ascertain the bioaccessibility of arsenate and changes in arsenate surface speciation caused by the biofluid systems. The effects of organic matter on arsenate bioaccessibility were investigated by adding oxalic and vanllic acid to biofluid systems. These results suggest that the bioaccessibility of arsenate is increased by organic matter and increasing reaction time.
\end{abstract}

\section{INTRODUCTION}

Potential exposure to arsenic (As) basically through ingesting or breath from tailings may pose a risk to human health. In physiological systems of the human body, some of the uptake arsenic may become soluble (Meunier et al., 2010). That is the presence or the artificial addition of natural organic matter may influence the mobility of arsenic previously adsorbed onto soil or tailings particle surfaces (Redman et al., 2002; Wang \& Mulligan, 2009). The in vitro bioassays in this work were carried out in simulated biofluid reacted with several minerals and organic matter. Two synthetic systems included gastric and alveolar simulation biofluid. Ferrihydrite, scorodite and goethite are represented as typical iron oxide minerals in nature. Two representative organic matter, oxalic acid and vanillic acid, represented alkanes and aromatic hydrocarbons. Arsenate was operated in the assays as it is the common arsenic speciation in tailings.

\section{METHODS AND EXPERIMENTAL}

\subsection{In vitro bioassay}

A physiologically based extraction test (PBET) was used to estimate the bioaccessibility of arsenic from $\mathrm{As}(\mathrm{V})$-containing minerals, as well as from samples mixed with and without natural organic matter.

\subsection{Estimation of arsenic bioaccessibility}

Arsenate bioaccessibility was calculated by dividing the arsenate concentration $(\mu \mathrm{g} / \mathrm{g})$ measured in the in vitro gastric solution or the in vitro alveolar solution by the total soil arsenate concentration $\left(\mu \mathrm{g} \mathrm{g}^{-1}\right)$, as described by the following equation (Rodriguez \& Basta, 1999; Pouschat \& Zagury, 2006):

As bioaccessibility $(\%)=($ in vitro As $) /($ Total As $) \times 100$

\section{RESULTS AND DISCUSSION}

\subsection{Arsenate bioaccessibility}

The in vitro bioassay showed that the bioaccessible As in the $\mathrm{As}(\mathrm{V})$-ferrihydrite, scorodite and $\mathrm{As}(\mathrm{V})$ goethite is intermediate (bioaccessibility: 6.96 to $15.77 \%)$. As(V)-ferrihydrite showed the lowest total As release content (G: 26.35 to $56.99 \mathrm{mg} \mathrm{L}^{-1}$ and A: 9.23 to $21.89 \%$ ), but the highest As bioaccessibility (G: 17.57 to $38.01 \%$ and A: 6.16 to $14.60 \%$ ). In the study, organic carbon concentration $(\sim 0.1 \mathrm{wt} \%)$ and minerals levels $(\sim 1 \mathrm{wt} \%)$ suggest that mineralogical characteristics and organic matter content play important roles in the As bioaccessibility of the minerals. The effects of two representative organic matter, oxalic acid and vanillic acid represented alkanes and aromatic hydrocarbons, are similar to different minerals in gastric and alveolar biofluids. It shows that organic acid increases arsenate bioaccessibility and $\mathrm{As}(\mathrm{V})$ content in biofluid. With increasing $\mathrm{As}$ and $\mathrm{Fe}$ concentrations, the relative gastric and alveolar bioaccessibility decreased similarly, despite the different chemical conditions of the two extraction fluids (e.g., pH 1.8 vs 7.4, anaerobic and aerobic).

The sorption behavior of arsenate in soil is highly dependent on organic carbon, while the desorption 


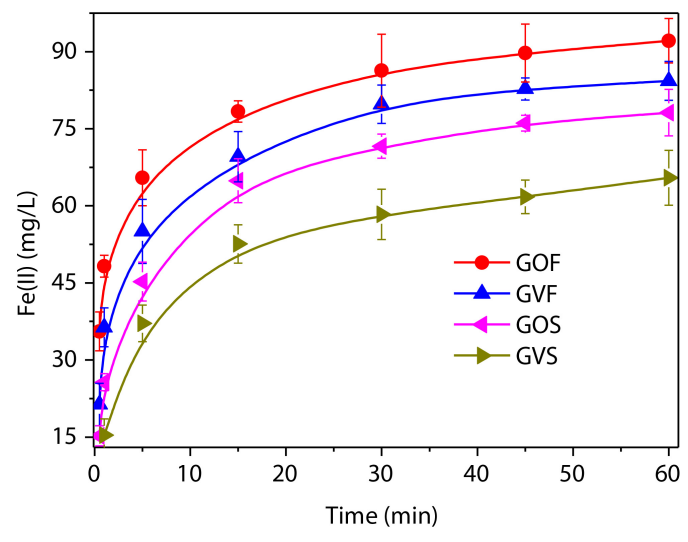

Figure 1. Ferrous concentration in simulated gastric biofluid with time.

is critically influenced by the high concentrations of amorphous and/or crystalline iron oxides. These factors control bioaccessibility after release of As from the crystalline mineral structure. In simulated bio-fluid systems, iron oxides dissolved at specific $\mathrm{pH}$, leading to arsenic release from surface of minerals and formation of ferric hydroxide colloid. A part of released arsenate was re-adsorbed on solid surface through complex with hydroxyl of minerals (Fendorf et al., 1997). Existing of organic matter influenced both the dissolution of minerals and arsenic re-adsorption.

\subsection{Species of Fe and As}

Speciation of As and Fe released were determined for three minerals. There was no detectable As(III) neither in the anaerobic gastric nor in the alveolar fluid. This means that $\operatorname{As}(\mathrm{V})$ was not reduced to more toxic As(III) even in anaerobic gastric phase. It is a good phenomenon considering human health. The assay indicated that the $\mathrm{Fe}$ that was solubilized during the alveolar phase was totally $\mathrm{Fe}(\mathrm{III})$. At the $\mathrm{pH}$ of 7.4 of the alveolar phase, $\mathrm{Fe}$ (II) would be soluble, but Fe(III) is insoluble. Speciation of $\mathrm{Fe}$ in gastric phase shows that detective $\mathrm{Fe}$ (II) occurred after organic matter addition (Fig. 1). $\mathrm{Fe}$ (II) was the $\mathrm{Fe}$ (III) reduction product by the organic substances (Theis \& Singer, 1974).

\subsection{Stoichiometry of release Fe and As}

Stoichiometry of release Fe and As uncovered minerals dissolution and arsenic desorption from solid surface. From the results of Fe:As, it shows that the ratios of $\mathrm{As}(\mathrm{V})$-Ferrihydrite and $\mathrm{As}(\mathrm{V})$-goethite in gastric phase were beyond adsorption ratio values, illustrating that As bioaccessibility derived from a dominant process of dissolution minerals. However, in alveolar phase, the ratios implied arsenic release attributed to As desorption from minerals. As for scorodite, a ratio of iron to arsenic nearly 1:1 crystallization mineral, its disintegration led to stoichiometry of release Fe and As very close to $1: 1$, regardless in gastric and alveolar phases.
Comparison of the same solids in two biofluid phases, shows a stoichiometric increment $\mathrm{Fe}$ and As with adding organic matter in gastric phase, and ox-alic acid increased more than vanllic acid. The results means that organic matter inhibited the process of mineral dissolution, while facilitated arsenic desorption. Ionization of organic matter produced hydrogen ions, which inhibited producing hydrogen ions of original gastric phase at the same $\mathrm{pH}$, and then hydroxide ions increased to maintain ion product, leading to increasing ferric hydroxide colloid, and finally improving mineral dissolution. A part of additional organic matter was adsorbed onto the surface of minerals. It was competitive with arsenic on surface activity sites, attributing to arsenic desorption, since organic matter occupied some adsorption sites and inhibited iron release from minerals.

\section{CONCLUSIONS}

Organic acid increased arsenic bioaccessibility in gastric and alveolar simulated biofluids. Iron species changed to ferrous iron to a certain extent. Arsenate was not transform to arsenite. The ratios of release $\mathrm{Fe}$ and As are 1:1 for the three minerals containing arsenate in the biofluids.

\section{ACKNOWLEDGEMENTS}

This research was supported by the National Natural Science Foundation of China (no. 41402214).

\section{REFERENCES}

Fendorf, S., Eick, M.J., Grossl, P. \& Sparks, D.L. 1997. Arsenate and chromate retention mechanisms on goethite 1 . Surface structure. Environ. Sci. Technol. 31(2): 315-320.

Meunier, L., Walker, S.R., Wragg, J., Parsons, M.B., Koch, I., Jamieson, H.E. \& Reimer, K.J. 2010. Effects of soil composition and mineralogy on the bioaccessibility of arsenic from tailings and soil in gold mine districts of Nova Scotia. Environ. Sci. Technol. 44(7): 2667-2674.

Pouschat, P. \& Zagury, G.J. 2006. In vitro gastrointestinal bioavailability of arsenic in soils collected near CCA-treated utility poles. Environ. Sci. Technol. 40(13): 4317-4323.

Redman, A.D., Macalady, D.L. \& Ahmann, D. 2002. Natural organic matter affects arsenic speciation and sorption onto hematite. Environ. Sci. Technol. 36(13): 2889-2896.

Rodriguez, R.R. \& Basta, N.T. 1999. An in vitro gastrointestinal method to estimate bioavailable arsenic in contaminated soils and solid media. Environ. Sci. Technol. 33(4): 642-649.

Theis, T.L. \& Singer, P.C. 1974. Complexation of iron(II) by organic matter and its effect on iron(II) oxygenation. Environ. Sci. Technol. 8(6): 569-573.

Wang, S.L. \& Mulligan, C.N. 2009. Effect of natural organic matter on arsenic mobilization from mine tailings. $J$. Hazard. Mater. 168(2-3): 721-726. 